\title{
DEGRADATION STUDYOF PIMAVANSERIN: IDENTIFICATION, ISOLATION AND STRUCTURAL CHARACTERIZATION OF DEGRADANTS
}

\author{
Shaik. John Saida ${ }^{1,2, *}$, A. Manikandan", V.V.S.R.N. Anji Karun Mutha ${ }^{2}$, \\ Muralidharan Kaliyaperumal', Chidananda Swamy Rumalla ${ }^{2}$, Ramulu \\ Yanaka $^{2}$ and S. Venkat Rao ${ }^{3}$ \\ ${ }^{1}$ Department of Chemistry, Bharath Institute of Higher Education and Research, Selaiyur, \\ Chennai-600073, Tamil Nadu, India \\ ${ }^{2}$ Department of Discovery Chemistry, GVK BiosciencesPvt. Ltd., Hyderabad-500076, \\ Telangana State, India. \\ ${ }^{3}$ Department of Organic Chemistry, SMS Pharmaceuticals Ltd., R\&D Centre (ADSIR \\ Approved Facility), Hyderabad-500043, Telangana State, India. \\ *E-mail: saida_sk2005@yahoo.co.in
}

\begin{abstract}
Pimavanserin (PMV) is a novel antipsychotic drug that is used for the treatment of Parkinson's disease and psychosis. PMV stability is characterized by subjecting it to systematic forced degradation in various stress conditions such as acid, base, peroxide, UV-light and heat as per ICH guidelines. Three PMV degradants were identified, one each from acid, base and peroxide catalysed degradation. All the three PMV degradants were isolated on $\mathrm{C} 18$ column by using preparative HPLC with gradient elution method and labelled as DP-1, DP-2 and DP-3, and their structures were elucidated by mass and 2D NMR spectral analysis. DP-1 was identified as bis (4isobutoxyphenyl) methane, DP-2 was identified as1,3-bis(4-isobutoxybenzyl)urea and DP-3 was identified as Noxide product of PMV. Interestingly, both acid and base degradation products of PMV (DP-1 and DP-2) contain Iso butoxy benzyl amine portion of the drug which is stable, and the remaining fragment of PMV is sensitive to stress. PMV degradation products, DP-1 and DP-2 were confirmed as dimers, and DP-3 as N-oxide product resulting from the peroxide mediated oxidation. Furthermore, PMV was found to be stable for $48 \mathrm{hrs}$ when exposed to UV-light and subjected to $70{ }^{\circ} \mathrm{C}$.
\end{abstract}

Keywords: Pimavanserin, Degradation Products, UPLC-MS, NMR.

(C) RASĀYAN. All rights reserved

\section{INTRODUCTION}

Pimavanserin (PMV) is an atypical antipsychotic drug, approved in the year 2014 by FDA for the treatment of delusions and hallucinations with psychosis, affected with Parkinson's disease ${ }^{1}$. PMV, unlike other atypical antipsychotics, does not act through dopamine receptor antagonism but acts as an inverse agonist and antagonist of serotonin (5HT2A) receptors ${ }^{2-4}$. PMV is also being studied for the treatment of schizophrenia, depression and agitation. During PMV synthesis, two process impurities were identified and reported as 1, 3-bis (4-isobutoxybenzyl) urea and N-oxide (4-(1-(4-fluorobenzyl)-3-(4isobutoxybenzyl) ureido)-1-methylpiperidine 1-oxide) ${ }^{5-6}$. Koduri et.al. studied and reported the stability of PMV in bulk and tablet dosage form using HPLC without much attention to the structural characterization of degradation products ${ }^{7}$. Shixiao Wang et.al has developed UPLC-MS/MS Method for Determination of Pimavanserin Tartrate in Rat Plasma ${ }^{8}$. To the best of our knowledge, a detailed PMV stability study was not reported in the literature. Hence, in the present research, we conducted a systematic PMV stability study for the first time as per the ICH guidelines ${ }^{9-10}$, and identified the degradation products by UPLC-MS, isolated by preparative HPLC and further degradant structures were

Rasayan J. Chem., 13(1), 222-229(2020)

http://dx.doi.org/10.31788/RJC.2020.1315579

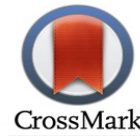




\section{RASĀYAN J. Chem.}

Vol. 13 | No. 1 |222 - 229| January - March | 2020

elucidated by 2D NMR. PMVacid and base degradation products contain Iso butoxy benzyl amine portion of the drug which is stable, and the remaining fragment of PMV is sensitive to stress.

\section{EXPERIMENTAL}

\section{Materials and Methods}

Pimavanserin (PMV) drug substance (API) was a kind gift from SMS Pharmaceuticals Limited, R\&D center, Hyderabad, Telangana state, India. Acetonitrile and Formic acid were procured from Merck, USA. Dimethyl sulfoxide-d6 containing $0.03 \%$ (v/v) of TMS was purchased from Cambridge Isotope Ltd., UK. Milli-Q water is collected from the in-house Millipore instrument. All reagents used are of the highest purity.

\section{Pimavanserin Degradation Study}

PMV degradation study was conducted as per ICH guidelines ${ }^{9-10}$ and details of stress conditions are summarized in Table-1. In brief, for acid hydrolysis, $500 \mathrm{mg}$ of PMV was solubilized in $5.0 \mathrm{~mL}$ of $0.5 \mathrm{~N}$ Hydrochloric acid solution and refluxed for $12 \mathrm{~h}$ at RT. For base degradation, $500 \mathrm{mg}$ of PMV was solubilized in $5.0 \mathrm{~mL}$ of $0.5 \mathrm{~N}$ Sodium hydroxide solution and refluxed for $12 \mathrm{hr}$ at RT. For oxidative degradation, $500 \mathrm{mg}$ of PMV was solubilized in $5.0 \mathrm{~mL}$ of $30 \% \mathrm{H}_{2} \mathrm{O}_{2}$ and refluxed for $48 \mathrm{hr}$ at RT. For heat stress, $500 \mathrm{mg}$ of PMV was kept in an oven at $70{ }^{\circ} \mathrm{C}$ for $48 \mathrm{hr}$. The resultant degradation solutions were diluted in $100 \mathrm{~mL}$ of water:acetonitrile::50:50. For photolytic stress, $500 \mathrm{mg}$ of PMV was kept under UV light for $48 \mathrm{hr}$. The resultant degradation solution was diluted in $100 \mathrm{~mL}$ of water:acetonitrile::50:50.

\section{Liquid Chromatography-Mass Spectrometry (UPLC-MS)}

PMV acid degradation study samples were analyzed by using Thermo Ion trap mass analyzer (LCQ FLEET) and alkali, oxidative, UV and heat degradation study samples were analyzed on Waters UPLCMS instrument with a single quadrupole mass analyzer.

PMV acid degradation study samples along with the freshly prepared sample with identical treatment were diluted with water:acetonitrile:: 50:50 and injected on to the Acquity column; BEH C18 (2.1 mm x $50 \mathrm{~mm} \times 1.7 \mu)$ and the peaks were resolved using gradient flow method with mobile phase A: $0.1 \%$ Formic acid in water and mobile phase B: $0.1 \%$ Formic acid in acetonitrile, \% B: 0/3, 0.3/3, 2.8/98, $4.5 / 98,4.51 / 3,5.5 / 3$. And mass parameters are with ion source ESI mode, and source parameters capillary voltage: $15 \mathrm{~V}$, cone voltage: $3.5 \mathrm{KV}$, source temp: $380^{\circ} \mathrm{C}$, sheath gas: $40 \mathrm{~L} / \mathrm{hr}$, aux gas: $8 \mathrm{~L} / \mathrm{hr}$. the sample was analyzed in a negative mode.

PMV alkali, oxidative, UV and heat degradation study samples along with freshly prepared samples with identical treatment were diluted with water: acetonitrile::50:50 and injected on to the X-Bridge C18 column $(3.0 \mathrm{~mm} \times 50 \mathrm{~mm} \times 2.5 \mu)$ and the peaks were resolved using gradient flow method with mobile phase A: $10 \mathrm{mM}$ ammonium acetate in water and mobile phase B: acetonitrile, \%B: 0/5, 3/100, 4.5/100, 4.7/5, 5.5/5. And mass parameters, Waters SQD with ion source ESI mode, and various source parameters capillary voltage: $3.5 \mathrm{~V}$, cone voltage: $50 \mathrm{~V}$ source temp: $359^{\circ} \mathrm{C}$, desolvation gas: $750 \mathrm{~L} / \mathrm{hr}$, cone gas: $50 \mathrm{~L} / \mathrm{hr}$ samples were analyzed in positive mode.

\section{Preparative HPLC}

PMV acid, base, and oxidative degradation crude substance was diluted in a mixture of water and acetonitrile (50:50), degradant peaks were collected by Gilson preparative HPLC equipped with module $331 \& 332$, diode array detector at $215 \& 254 \mathrm{~nm}$, Kromasil C18 column $(19 \mathrm{~mm}$ x150 mm x $5.0 \mu)$, mobile phase A: $10 \mathrm{mM}$ ammonium bicarbonate in water and mobile phase $\mathrm{B}$ : acetonitrile with gradient elution method, \%B: 0/10, 12/85, 17/85, 18/10,20/10 at a flow of $16 \mathrm{~mL} / \mathrm{min}$.

\section{Nuclear Magnetic Resonance (NMR) Spectroscopy}

PMV acid, base, and oxidative degradation products, $5 \mathrm{mg}$ of each were solubilized in $0.6 \mathrm{~mL}$ of Dimethyl sulfoxide-d6 and NMR data was recorded with a $500 \mathrm{MHz}$ instrument equipped with Broadband observe probe $(\mathrm{BBO}) .{ }^{1} \mathrm{H},{ }^{13} \mathrm{CNMR}$ chemical shifts were recorded on $\delta$ scale in ppm with respect to tetramethylsilane (TMS) as an internal reference. 
RASĀYAN J. Chem.

Vol. 13 | No. 1 |222 - 229| January - March | 2020

\section{RESULTS AND DISCUSSION}

In the present study, PMV is subjected to acid, base, oxidative, UV and heat stress as per ICH guidelines ${ }^{9-}$

${ }^{10}$. PMV is stable in heat and photolytic conditions. PMV acid, base and peroxide mediated degradation peaks were resolved and analyzed by UPLC-MS. PMVacid degradation product eluted at retention time $4.26 \mathrm{~min}$ and it is labeled as DP-1, (Fig.-1 and Table-2). PMV base and oxidative degradation products eluted at RT $3.48 \mathrm{~min}$ and $2.60 \mathrm{~min}$ and labeled as DP-2 and DP-3, respectively (Fig.-1 and Table-2). The mass of DP-1, DP-2 and DP-3 were found to be m/z 311.31 in negative mode, $\mathrm{m} / \mathrm{z} 385.56$ in positive mode and $\mathrm{m} / \mathrm{z} 444.58$ in positive mode (Fig.-2), respectively. For structural characterization, PMV is subjected to acid, base and oxidative stress conditions, and degradation peaks were isolated by preparative HPLC and lyophilized to obtain solid compound. All the three degradation products (DP-1, DP-2 and DP-3) are characterized by LC-MS, 1D and 2D NMR analysis and their structures are illustrated in (Fig.3)
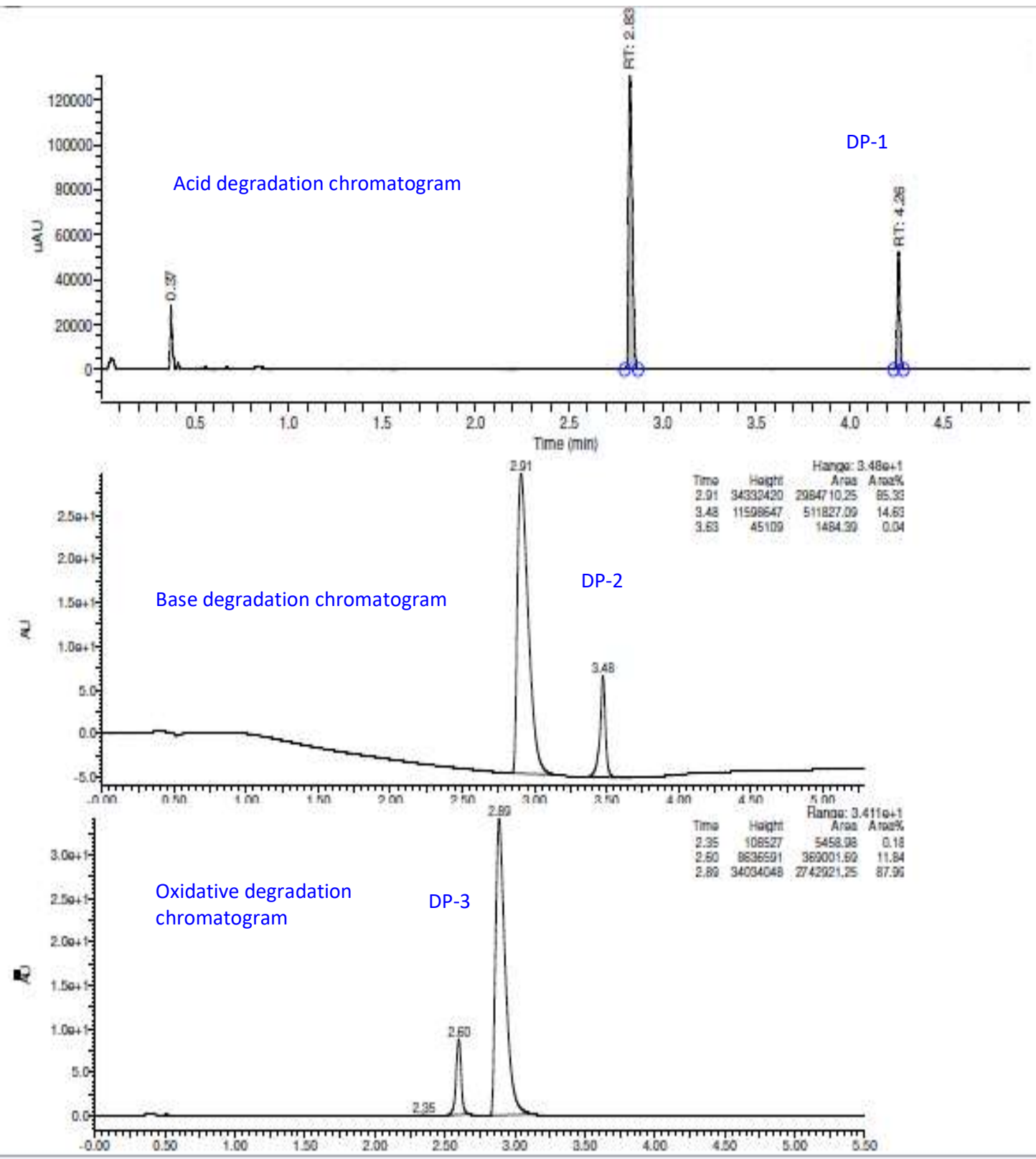

Fig.-1: Acid, Base, and Hydrogen Peroxide Degradation Chromatogram of Pimavanserin 
RASĀYAN J. Chem.

Vol. 13 | No. 1 |222 - 229| January - March | 2020

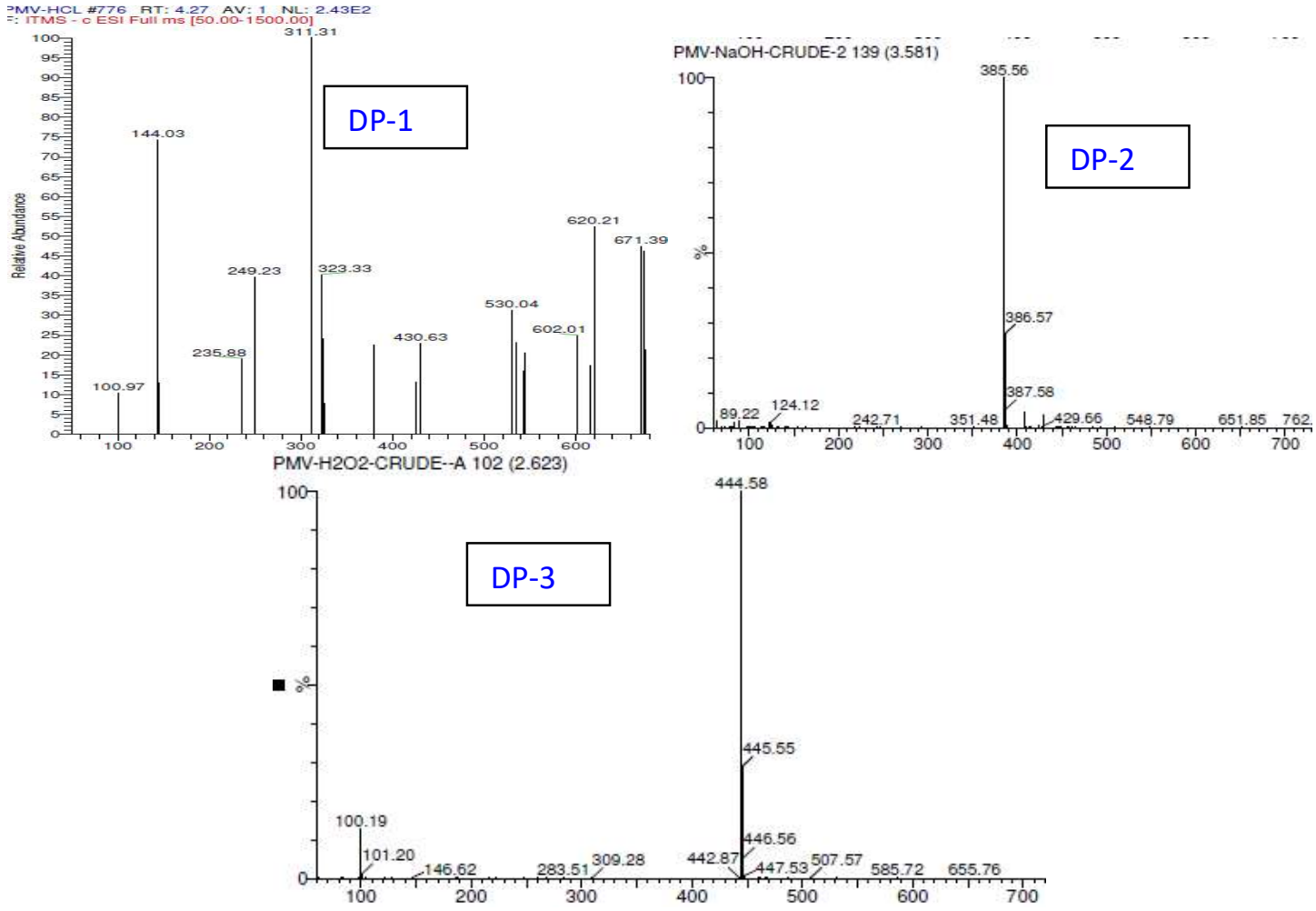

Fig.-2: Acid, Base, and Hydrogen Peroxide Degradation Mass Spectrum of Pimavanserin<smiles>CC(C)COc1ccc(CNC(=O)N(Cc2ccc(F)cc2)C2CCN(C)CC2)cc1</smiles>

Chemical Formula: $\mathrm{C}_{25} \mathrm{H}_{34} \mathrm{FN}_{3} \mathrm{O}_{2}$

$$
\text { Exact Mass: } 427.2635
$$

Molecular Weight: 427.5548

PIMAVANSERIN

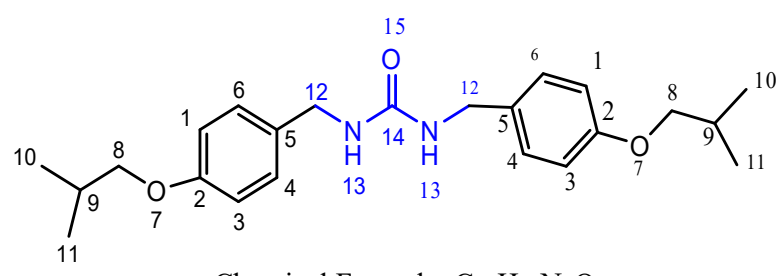

Chemical Formula: $\mathrm{C}_{23} \mathrm{H}_{32} \mathrm{~N}_{2} \mathrm{O}_{3}$

Exact Mass: 384.2413

Molecular Weight: 384.5118

DP-2<smiles>CC(C)COc1ccc(Cc2ccc(OCC(C)C)cc2)cc1</smiles>

Chemical Formula: $\mathrm{C}_{21} \mathrm{H}_{28} \mathrm{O}_{2}$

$$
\text { Exact Mass: } 312.2089
$$

Molecular Weight: 312.4458

$$
\text { DP-1 }
$$

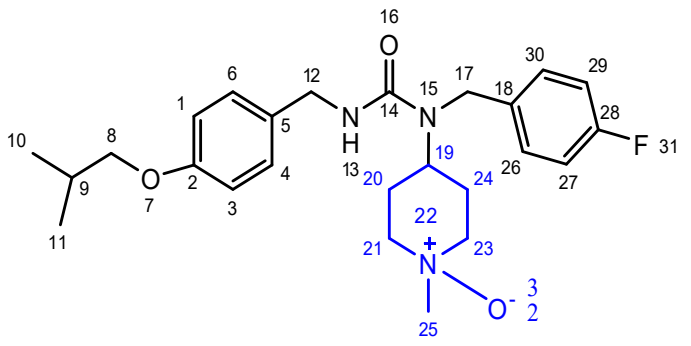

Chemical Formula: $\mathrm{C}_{25} \mathrm{H}_{34} \mathrm{FN}_{3} \mathrm{O}_{3}$

Exact Mass: 443.2584

Molecular Weight: 443.5542

DP-3

Fig.-3: Chemical Structures of Pimavanserin and its Degradation Products 
RASĀYAN J. Chem.

Vol. 13 | No. 1 | 222 - 229| January - March | 2020

Table-1: Acid, Base, Oxidative, Heat and Photolytic Stress Degradation Conditions

\begin{tabular}{c|c|c|c}
\hline Stress Methods & Degradation Conditions & Degradation Study at & Time \\
\hline Hydrolysis & Acid- $0.5 \mathrm{~N} \mathrm{HCl}$ & Room Temperature /stirring & 16 hours \\
\hline Hydrolysis & Base- $0.5 \mathrm{~N} \mathrm{NaOH}$ & Room Temperature /stirring & 16 hours \\
\hline Oxidation & $30 \%$ Hydrogen Peroxide & Room Temperature /stirring & 24 hours \\
\hline Dry Heat & Exposed to & $70{ }^{\circ} \mathrm{C}$ & 2 days \\
\hline Photolytic & Exposed to & Near UV lamp & 2 days \\
\hline
\end{tabular}

Table-2: Percent Pimavanserin and its Acid, Base and Oxidative Degradation Products

\begin{tabular}{c|c|c|c|c}
\hline $\begin{array}{c}\text { Degradation } \\
\text { method }\end{array}$ & $\begin{array}{c}\text { \% Pimavanserin } \\
\text { Recovered }\end{array}$ & $\begin{array}{c}\text { Degradation product } \\
\text { DP-1 (\%) } \\
\text { at RT 4.26 min }\end{array}$ & $\begin{array}{c}\text { Degradation product } \\
\text { DP-2 }(\%) \\
\text { at RT 3.48 min }\end{array}$ & $\begin{array}{c}\text { Degradation product } \\
\text { DP-3 }(\%) \\
\text { at RT 2.60 min }\end{array}$ \\
\hline Acid & 75.98 & 24.02 & 14.63 & \\
\hline Base & 85.33 & & & 11.84 \\
\hline Oxidative & 87.99 & - & - & - \\
\hline Thermal & - & - & - & - \\
\hline Photolysis & - & - & & \\
\hline
\end{tabular}

\section{DP-1 Structural Confirmation}

PMV acid degradation product, DP-1 mass spectrum revealed a deprotonated molecular ion peak with $m / z$ 311.31 in negative mode, corresponding to molecular formula $\mathrm{C}_{21} \mathrm{H}_{28} \mathrm{O}_{2}$. ${ }^{1} \mathrm{H}$ NMR spectra of DP-1 revealed six proton signals, two aromatic and 4 aliphatic. Proton NMR data of DP-1 showed 1-isobutoxy4-methylene benzene ring protons, similar to PMV with the exclusion of (1-(4-fluorobenzyl)-1-(1methylpiperidin-4-yl) urea). This suggests that during acid hydrolysis of PMV, C-12 and NH-13 bond is cleaved (Fig.-3). ${ }^{13} \mathrm{C}$ NMR spectrum of DP-1 showed 8 carbon signals, 4 aromatic and 4 aliphatic, in contrast to 28 signals in PMV. The mass spectrum of DP-1 confirms the presence of 21 carbon atoms, suggesting dimerization, which is confirmed by $2 \mathrm{D}$ NMR. ${ }^{1} \mathrm{H},{ }^{13} \mathrm{C}$ ppm values of DP-1 are presented in Table-3. Further, carbon-hydrogen connectivity's in DP-1 is confirmed by HMBC (Fig.-4).

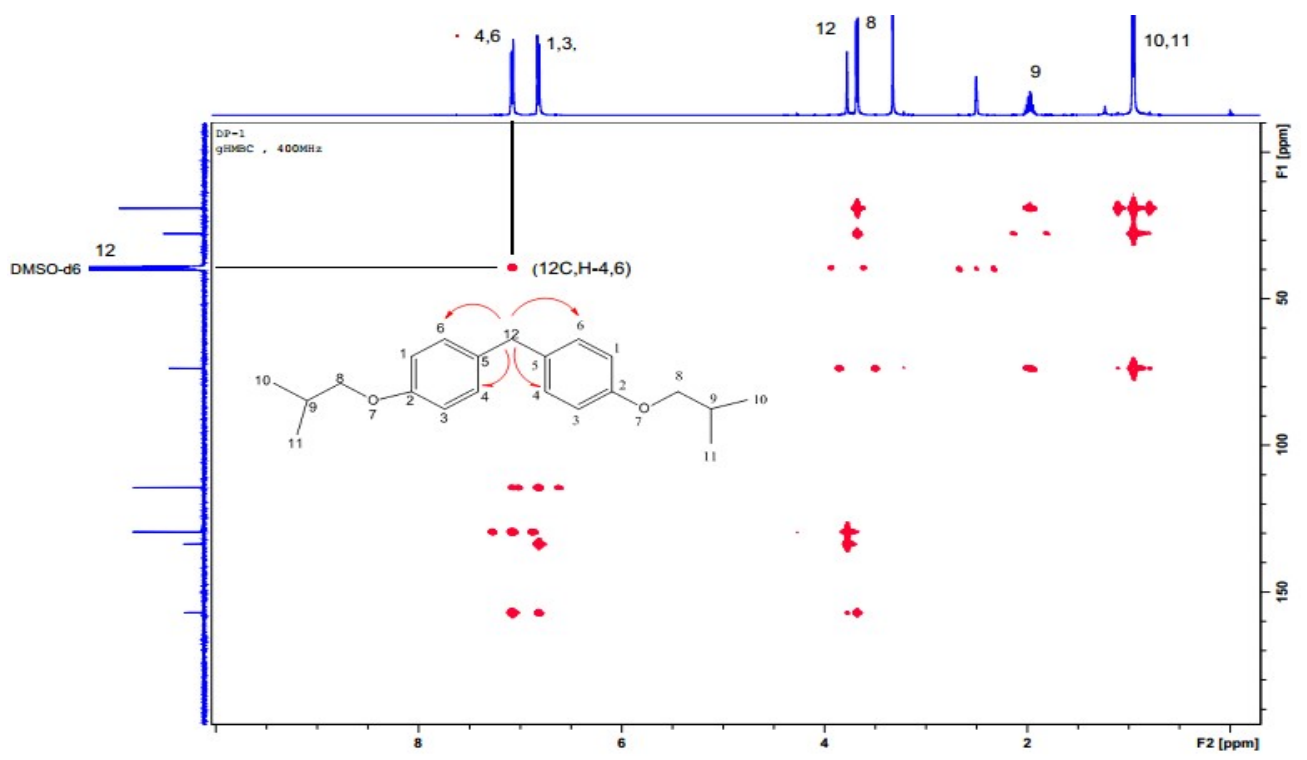

Fig.4: HMBC spectrum of DP-1

\section{DP-2 Structural Confirmation}

PMV base degradation product, DP-2 mass spectral data revealed a molecular ion peak with $\mathrm{m} / \mathrm{z} 385.56$ $[\mathrm{M}+\mathrm{H}]^{+}$in positive mode, confirms to chemical formula $\mathrm{C}_{23} \mathrm{H}_{32} \mathrm{~N}_{2} \mathrm{O}_{3}$. ${ }^{1} \mathrm{HNMR}$ spectra of DP-2 revealed 7 proton signals, 3 aromatic and 4 aliphatic. A comparison of ${ }^{1} \mathrm{H}$ NMR data of DP-2 with PMV revealed the presence of only 1-(4-isobutoxybenzyl) urea protons. This suggests bond cleavage between N-15, C-17 
RASĀYAN J. Chem.

Vol. 13 | No. 1 | 222 - 229| January - March | 2020

and N-15, C-19 positions of PMV (Fig.-3). DP-2 ${ }^{13} \mathrm{C}$ NMR shows 9 carbon signals, 5 aromatic and 4 aliphatic in contrast to 28 signals in PMV. The mass spectrum of DP-2 confirms the presence of 23 carbon atoms, suggesting dimerization, which is confirmed by $2 \mathrm{D}$ NMR. ${ }^{1} \mathrm{H},{ }^{13} \mathrm{C}$ ppm values of DP-2 are presented in Table-3. Further carbon-hydrogen connectivity's in DP-2 is confirmed by HMBC (Fig.5).

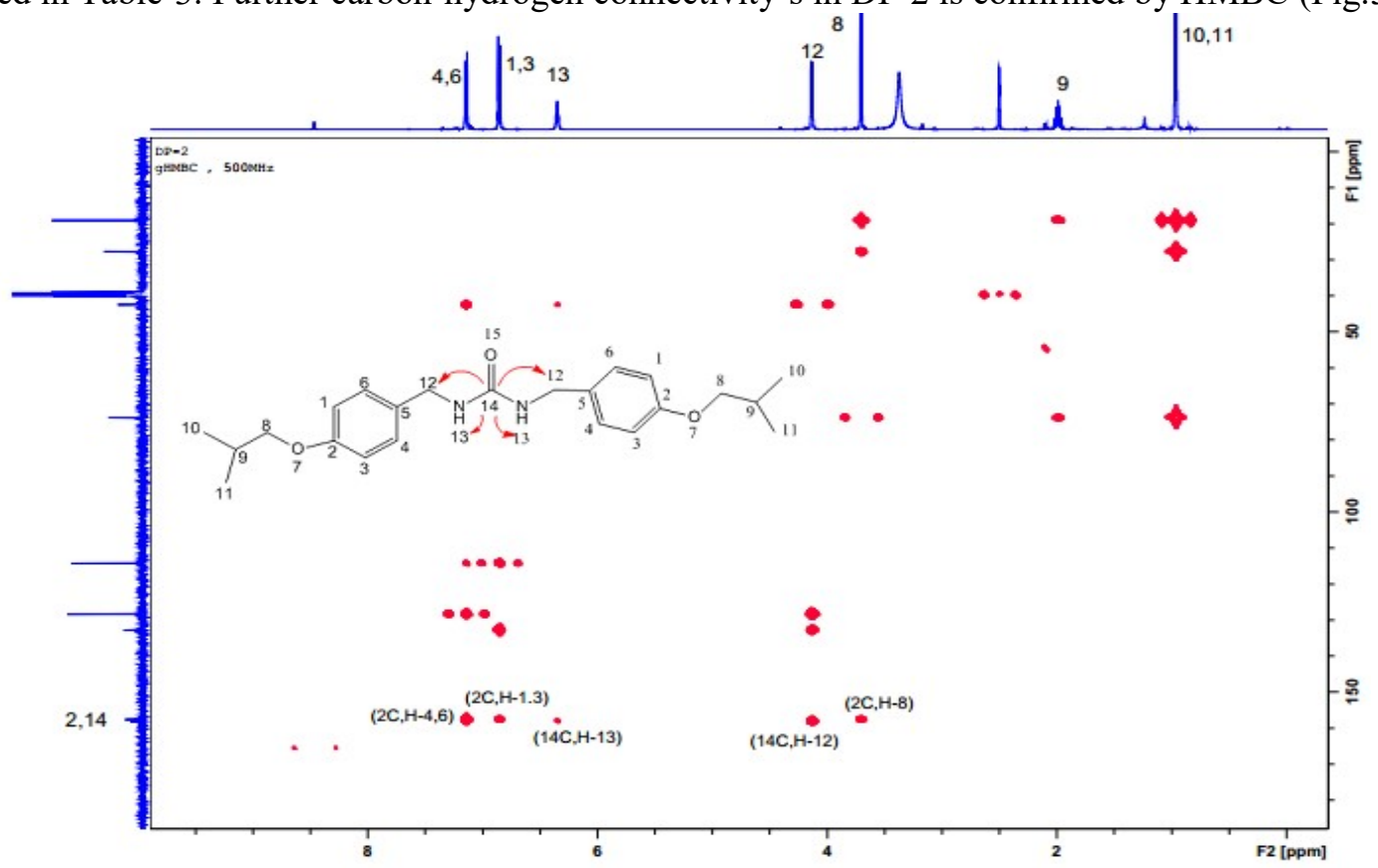

Fig.5: HMBC spectrum of DP-2

DP-3 Structural Confirmation

PMV oxidative degradation product, DP-3 mass spectrum revealed a protonated molecular ion peak with $\mathrm{m} / \mathrm{z} 444.58[\mathrm{M}+\mathrm{H}]{ }^{+}$confirms to molecular formula $\mathrm{C}_{25} \mathrm{H}_{34} \mathrm{FN}_{3} \mathrm{O}_{3}$. DP-3 mass (m/z 444.58) is 16units higher than PMV mass ( $\mathrm{m} / \mathrm{z}$ 427.26), suggesting peroxide mediated oxidation. DP-3 ${ }^{1} \mathrm{H}$ NMR spectrum revealed 25 aliphatic hydrogens, 8 aromatic and one exchangeable amide hydrogen. ${ }^{13} \mathrm{C}$ NMR spectrum revealed 12 aliphatic carbons and 13 aromatic carbons. ${ }^{1} \mathrm{H},{ }^{13} \mathrm{C}$ chemical shift values for DP3 were shown in Table-3. The number of proton and carbon signals in DP-3 and PMV are similar, with comparative drastic chemical shifts observed for few protons and carbons in DP-3 with respect to PMV. C-25 Nmethyl protons in PMV shifted from $2.29 \mathrm{ppm}$ to $2.99 \mathrm{ppm}$ in DP-3. Further, H-21 and H-23 protons in PMV shifted from $2.30 \mathrm{ppm}$ and $2.96 \mathrm{ppm}$, to $2.89 \mathrm{ppm}$ and 3.33ppm, respectively in DP-3. Similarly, H20, H-24 protons in DP-3 moved to the downfield comparedto PMV as represented in Table-3. C-25 Nmethyl carbon resonance $44.3 \mathrm{ppm}$ in PMV shifted to downfield $60.5 \mathrm{ppm}$ in DP-3. C-21 and C-23 carbon chemical shifts in PMV shifted from $53.8 \mathrm{ppm}$ to $64.8 \mathrm{ppm}$ in DP-3. These changes in proton and carbon chemical shift values suggest oxidation on N-22 position in PMV (Fig.-3).

Table-3: ${ }^{1} \mathrm{H}$ and ${ }^{13} \mathrm{C}$ NMR Data of Pimavanserin and its Degradation Products DP-1, DP-2 and DP-3.

\begin{tabular}{c|c|c|c|c|c|c|c|c}
\hline \multirow{2}{*}{ Assignment } & $\begin{array}{c}{ }^{1} \mathrm{H}(\mathrm{PPM}) \\
\text { API- } \\
\text { Drug }\end{array}$ & $\begin{array}{c}{ }^{13} \mathrm{C} \\
(\mathrm{PPM}) \\
\text { API- } \\
\text { Drug }\end{array}$ & $\begin{array}{c}{ }^{1} \mathrm{H}(\mathrm{PPM}) \\
\mathrm{DP}-1\end{array}$ & $\begin{array}{c}{ }^{13} \mathrm{C} \\
(\mathrm{PPM}) \\
\mathrm{DP}-1\end{array}$ & $\begin{array}{c}{ }^{1} \mathrm{H}(\mathrm{PPM}) \\
\mathrm{DP}-2\end{array}$ & $\begin{array}{c}{ }^{13} \mathrm{C}(\mathrm{PPM}) \\
\mathrm{DP}-2\end{array}$ & $\begin{array}{c}{ }^{1} \mathrm{H}(\mathrm{PPM}) \\
\mathrm{DP}-3\end{array}$ & $\begin{array}{c}{ }^{13} \mathrm{C}(\mathrm{PPM}) \\
\mathrm{DP}-3\end{array}$ \\
\hline 1 & 6.83 & 114.1 & 6.82 & 114.3 & 6.85 & 114.7 & 6.83 & 114 \\
\hline 2 & - & 157.4 & - & 156.9 & - & 157.6 & - & 157.4 \\
\hline 3 & 6.83 & 114.1 & 6.82 & 114.3 & 6.85 & 114.7 & 6.83 & 114 \\
\hline 4 & 7.1 & 128.1 & 7.08 & 129.5 & 7.14 & 128.8 & 7.09 & 128.1 \\
\hline 5 & - & 133 & - & 133.6 & - & 132.7 & - & 133 \\
\hline 6 & 7.1 & 128.1 & 7.08 & 129.5 & 7.14 & 128.8 & 7.09 & 128.1 \\
\hline 7 & - & - & - & - & - & - & - & - \\
\hline 8 & 3.70 & 74 & 3.68 & 73.7 & 3.7 & 73.7 & 3.70 & 73.7 \\
\hline
\end{tabular}


RASĀYAN J. Chem.

Vol. 13 | No. 1 | 222 - 229| January - March | 2020

\begin{tabular}{|c|c|c|c|c|c|c|c|c|}
\hline 9 & 1.99 & 27.7 & 1.97 & 27.7 & 1.99 & 27.7 & 1.99 & 27.6 \\
\hline 10 & 0.96 & 19 & 0.95 & 19.0 & 0.86 & 19.05 & 0.96 & 19.1 \\
\hline 11 & 0.96 & 19 & 0.95 & 19.0 & 0.96 & 19.05 & 0.96 & 19.1 \\
\hline 12 & 4.18 & 43.1 & 3.78 & 39.5 & 4.03 & 42.4 & 4.18 & 43.1 \\
\hline 13 & 6.89 & - & & & 6.35 & - & 6.93 & - \\
\hline 14 & - & 157.4 & & & - & 158.0 & - & 157.4 \\
\hline 15 & - & - & & & & & - & - \\
\hline 16 & - & - & & & & & - & - \\
\hline 17 & 4.41 & 44.03 & & & & & 4.44 & 44.1 \\
\hline 18 & - & 136.7 & & & & & - & 136.6 \\
\hline 19 & 4.02 & 51.1 & & & & & 4.15 & 49.8 \\
\hline 20,24 & $1.50,1.69$ & 28.66 & & & & & $2.27,1.33$ & 24.8 \\
\hline 21,23 & $2.30,2.96$ & 53.8 & & & & & $3.33,2.89$ & 64.8 \\
\hline 22 & - & - & & & & & - & - \\
\hline 25 & 2.29 & 44.3 & & & & & 2.99 & 60.5 \\
\hline 26,30 & 7.24 & 128.3 & & & & & 7.25 & 128.3 \\
\hline 27,29 & 7.12 & 114.8 & & & & & 7.12 & 114.8 \\
\hline 28 & - & 160.8 & & & & & - & 160.8 \\
\hline
\end{tabular}

Koduri $e t . a l^{7}$, for the first time studied the stability of PMV in API and formulationsas per ICH guidelines using HPLC-UV and reported as photo and heat-labileand it is further unstable in acid, base and oxidative stress conditions. The reported degradants peaks in HPLC-UV chromatogram is identical and formed to the same extent in all the stress conditions. In the present study, we conducted the systematic forced degradation studies of PMV as per ICH guidelines and characterized the structure of degradation products for the first time. In our studies, PMV was found to be stable upon exposure to UV light (for $24 \mathrm{hrs)} \mathrm{and}$ heat $\left(70{ }^{\circ} \mathrm{C}\right.$ for $\left.24 \mathrm{hrs}\right)$, which is contradictory to Koduri et.al ${ }^{7}$. PMV in acid, base and oxidative stress conditions gives rise to degradation products, DP-1, DP-2 and DP-3, respectively. DP-1is characterized as bis(4-isobutoxyphenyl)methane, DP-2 is characterized as 1,3-bis(4-isobutoxybenzyl)urea and DP-3 is characterized as 4-(1-(4-fluorobenzyl)-3-(4-isobutoxybenzyl)ureido)-1-methylpiperidine 1-oxide). DP-2 and DP-3 are reported as process related impurity ${ }^{5-6}$. However, we report for the first time, PMV degradation products: DP-2 and DP-3 are formed in the basic and oxidative degradation conditions, which is helpful in monitoring the PMV manufacturing process to reduce the potential impurities. PMV acid degradation product (DP-1), bis(4-isobutoxyphenyl)methane is a novel degradant formed by C12 and N13 bond cleavage, and further dimerization of 4-isobutoxyphenyl methane fragment.

\section{CONCLUSION}

PMV is stable upon exposure to UV light and heat. PMV forms three degradation products, one each in acid (DP-1), base (DP-2) and oxidative (DP-3) stress conditions. DP-1, DP-2, and DP-3 were isolated by preparative HPLC, mass was identified by UPLC-MS and structures were elucidated by 2D NMR. DP-2 and DP-3 were reported earlier as a PMV process impurity and a metabolite in vivo clinical plasma samples $^{5-6}$, respectively. We have identified the formation of DP-2 in basic and DP-3 in oxidative conditions for the first time. DP-1 is the novel PMV degradant product formed by the dimerization of 4isobutoxyphenyl methane fragment. To the best of our knowledge, the present study is the most comprehensive PMV degradation study with structural elucidation of degradants.

\section{ACKNOWLEDGMENT}

Authors would like to thank GVK Biosciences Pvt Ltd. management for supporting this work and, would also like to thank Dr. Ansar Ali Khan, Associate Director, and GVK Biosciences Pvt. Ltd. for his critical review of the manuscript.

\section{J. H. Friedman, Expert Opinion on Pharmacotherapy, 14(14), 1969(2013),} DOI: $10.1517 / 14656566.2013 .819345$

2. R. H. Howland, Journal of Psychosocial Nursing and Mental Health Services, 54(6), 21(2016), DOI: 10.3928/02793695-20160523-01 
RASĀYAN J. Chem.

Vol. 13 | No. 1 | 222 - 229| January - March | 2020

3. U. Hacksell, E. S. Burstein, K. McFarland, R. G. Mills, and H. Williams, Neurochemical Research, 39(10), 2008(2014), DOI:10.1007/s11064-014-1293-3

4. S. Ancoli-Israel, K. E. Vanover, David M. Weiner, Robert E. Davis, Sleep Medicine, 12(2), 134(2011), DOI:10.1016/j.sleep.2010.10.004

5. Shenyang Pharmaceutical University; Wang Shaojie; Peng Liangsheng, CN107216271A (2017).

6. Hack Sell-Patent Application publication, United states, US0082388A1(2009)

7. Geetha Bhavani Koduri, Hari Babu Bollikolla, Ramachandran Dittakavi, Srinivasu Navuluri, Pharmaceutical Sciences, 24, 291(2018), DOI: 10.15171/PS.2018.42

8. S. Wang, Y. Wang, S. Gao, Y. Zhang, H. Wang, L. Zhao, Journal of Pharmaceutical Analysis, 7(6), 406(2017), DOI:10.1016/j.jpha.2017.07.0 04

9. International Conference on Harmonization (ICH) of Technical Requirements for the Registration of Pharmaceutical For Human Use, ICH Harmonized Tripartite Guideline, Stability testing of new drugs substance and products Q1A (R2), Geneva, Switzerland (2003).

10. International Conference on Harmonization, ICH Guidelines, Validation of Analytical Procedures Technical Requirements for Registration of Pharmaceuticals For Human Use: Text and Methodology Q2A (R1), International Conference on Harmonization. Geneva, Switzerland (2005).

[RJC-5579/2019] 